\title{
IMPLEMENTATION OF SIX SIGMA TOOLS TO IMPROVE SUPPLY CHAIN EFFICIENCY OF AN ELECTRONIC GOODS MANUFACTURING INDUSTRY
}

\author{
Aniruddha Bavdhankar ${ }^{*}$, Jayant Karajagikar ${ }^{1}$, Vicky Sardar ${ }^{2}$, Vishal Sonawane ${ }^{3}$ and \\ Atul Chaudhari ${ }^{3}$ \\ ${ }^{I}$ Dept. of Production Engineering and Industrial Management, College of Engineering, Pune, India \\ ${ }^{2}$ Research Associate Design and Innovation Centre (DIC), College of Engineering, Pune, India \\ ${ }^{3}$ Symtronics Automation (India) Pvt. Ltd. Pune, India
}

\begin{abstract}
Increase in competencies in global markets enforce the organizations to reduce their total cost structure, increase quality, efficiency, and production capability without increasing capital investment for topline growth. To achieve continuous growth and success in today's market nearly every business process needs improvement. Organizations must rely on effective supply chains, or networks, to compete and grow in the global market and networked economy. The optimal supply chain strategy plays an operational role in achieving economic, social and ecological performance. Due to the advancement in the cost reduction strategies, industries are concentrating on their supply chain management to achieve the optimality between the supply and demand. Many tools and methodologies are being devised to develop differentiated purchasing strategies. This case study explores the clubbed behavior of Six Sigma, DMAIC and Lean tools to prioritize the suppliers. The study also focuses on implementation of Six Sigma tools, and techniques in supply chain for an electronic device manufacturing firm based in Pune to improve its Key Performance Indices (KPIs). In addition, this methodology aids in physical inventory accuracy as well as reduce the lead time between on time delivery of shipments. The advantages of implementation of suggested solutions are that it will reduce total operational cost, improve supply chain efficiency, and rise in level of customer satisfaction.
\end{abstract}

Keywords: DMAIC, OTS, Lean System, Six Sigma, Supply Chain Management

\section{Introduction}

Increasing trends in technology and the revolutionary emergence of e-commerce is creating awareness among consumers. These added expectancies in the consumer sector, demands more transparency from the suppliers/manufacturers. Due to existing competencies, there is an observed inclination towards quality, customer satisfaction and decrease in lead time deliveries. Organisations are now concentrating more on optimization of the traditional techniques for the improvement in the existing processes. Maintaining a balance between the quality assurance and cost reduction strategies is a complicated task. Literature presents many strategies and traditional techniques to bridge the gap between supply and demand.

Lean Six Sigma project initiatives start with understanding the current state of the Business processes in organization, then setting up targets for future state of all activities. Six Sigma uses DMAIC (Define, Measure Analyse Improve and Control) framework and Lean uses tools like value stream mapping, 5S program, Single piece flow etc. Using these tools and techniques organization can improve business processes. The obstacles to achieve these improvements can be resolved by kaizen event. Improvement means increasing On Time Shipment (OTS), increasing inventory turnover, reduce process variation and cost, and improving the quality. The practice of Lean methods targets to waste reduction whereas Six Sigma methodology targets to reduce process variation. 
Variation in customer demands, advances of recent technologies in communication and information systems, competition in global environment, decreases in governmental regulations, and increases in environmental consciousness, have forced companies to focus on supply chain management. The "supply chain management" term has been used for almost 20 years and is defined as the integration of activities to procure materials, their transformation into intermediate goods and final products, and delivery to customers. The results obtained in the case study shows the positive effect of implementation.

The work focuses on increasing On Time Shipments from $65 \%$ to $85 \%$ hence it improves customer confidence and reduce product development cost with increasing inventory turnover from 7 to 16, which in turn will increase physical inventory accuracy from $53 \%$ to $95 \%$.

\section{Literature Review}

Understanding customer needs as well as how they value these needs shows the Lean Six Sigma improvement team what is most important to the external customer. This information can be used to identify and deploy Lean Six Sigma improvement projects. In this paper, concentration is on implementation of lean tools integrated with Six sigma method. The stated methodology is to be incorporated in existing system of supply chain management process of a custom-made electronics device manufacturing organisation.

Spare parts inventory needs to be treated differently than any other inventory for estimating the control and stocking policies. That means, as the demand is lumpy, uncertain for the quantity requirement and its consumption, spare parts inventory is a case which needs to be validated against statistical measures. It can be interpreted from the statistical formulations that, to forecast accurate estimates, all the distribution parameter like goodness of fit test should be studied for the formulation of any mathematical model or algorithm to achieve a balanced supply chain (Sardar and Rajhans, 2017). If organizations wish to achieve continuous quality improvement they need to use appropriate selection of quality tools and techniques. The principle of continuous improvement using the

seven basic quality tools which guarantee organizations to move from static to dynamic improvement status. The 7QC tools have an important place in data collecting, analysing, visualizing and all other phases in PDCAcycle, DMAIC and DMADV phases, and in Lean Six Sigma (Mirko Soković et al., 2009).

To balance a supply chain, the demand pattern needs to be analysed and sorted as compared to the huge data points available. Pareto analysis gives you an idea about exact quantity of spare parts which contributes to large amount of your inventory cost. The combined model of Pareto analysis and Spare part classification analysis gives better output in terms of cost saving. After applying spare part classification analysis to results of Pareto it gives you an idea about when to order and how much to order (Pathak et al, 2017). This paper clubs together the specific tools, methods and techniques that are relevant to supply chain analysis and optimization together into an organized format in one place to improve supply chain operational performance.

The primary goal of this research is to bring diverse topics and metrics together to understand their interrelationships and impact on supply chain performance. The study also introduces strategies to understand the relationships between process inputs (X's) and their impact on key process outputs(Y's) which will help to understand the famous Lean Six Sigma Relationship, $Y=f(X)$ in terms of inventory investments. (Martin, J. (2007))

\section{Methodology}

The organisation considered for this research is a medium-scale Project-based Organisation (PBO) producing complex industrial products and systems (CoPS). In contrast to the functional and matrix organisation, the project-based organisation (PBO) has been put forward as a form ideally suited for managing increasing product 
complexity, fast changing markets, cross-functional business expertise, customer focused innovation and market, and technological uncertainty. This applies particularly to high value, complex industrial products and systems (or 'CoPS'). The organisation is one of the leading manufacturers of electronic controls for Naval applications in India. The organisation is well versed in on-board feasibility studies, evolution of indigenous designs, obtaining design approvals, prototype development and qualification testing at defence labs, manufacture, installation, commissioning and aftersales support. The organisation has designed and supplied many electronic systems for the Indian Navy over the past two decades. The work flow at the industry illustrated in the Figure 1 below. How the material and information flows also how the different operations takes place at each level of business flow are shown in the following figure.

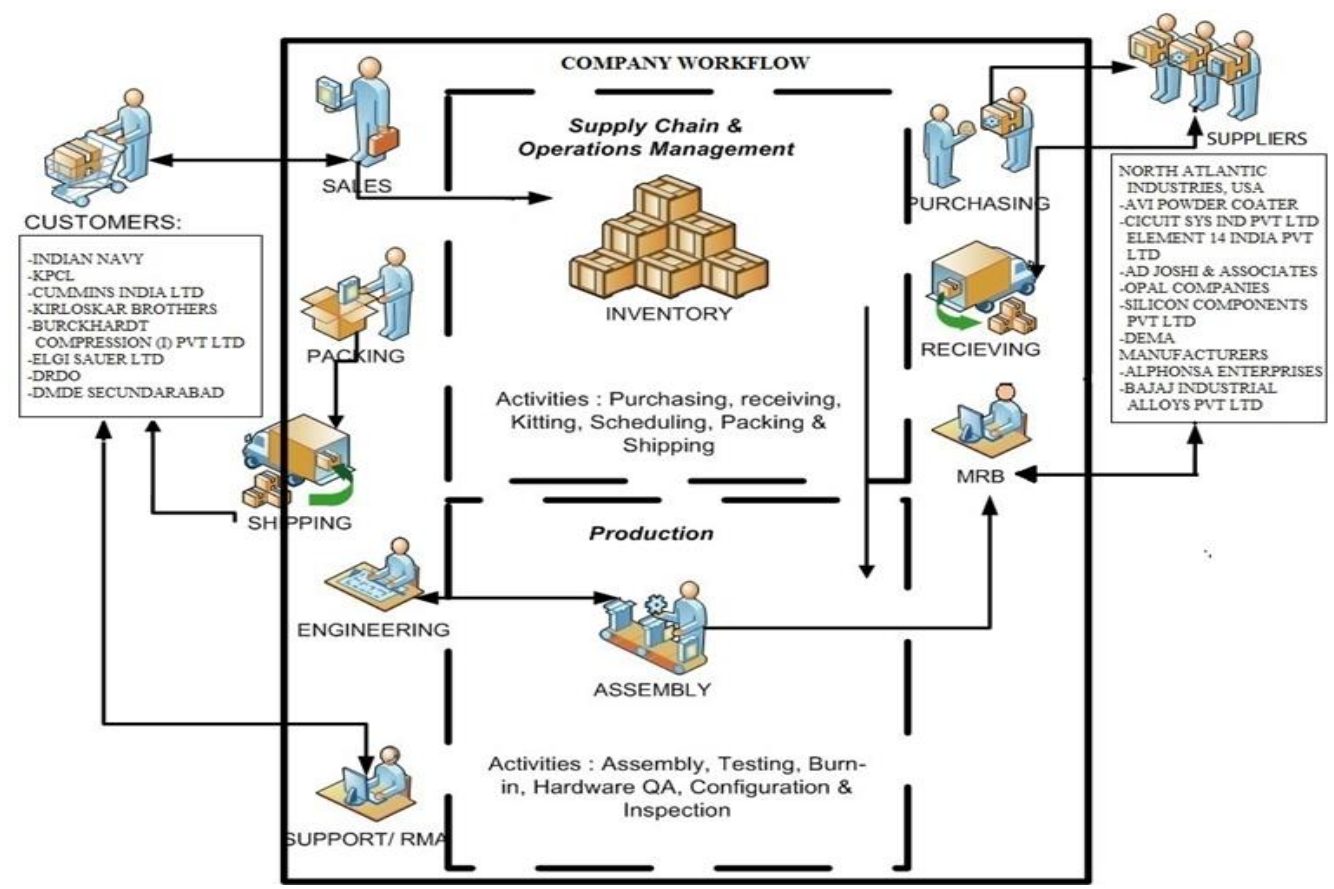

Figure 1: Graphical illustration of work flow from supplier to customer and internal processes at the organization

Improvement in supply chain management related Key Performance Indicators(KPIs) such as On Time Shipments (OTS), Material availability and addressing the supplier quality issues were studied to enhance customer experience at organisation. The study addresses the root causes of problems in the process of supply chain and recommends solutions and alternatives which should lead to more optimized business processes and enhance operational system, eliminate different type of waste, and increase the profit. Cross-functional teams were brought together to Analyse key supply chain metrics or key performance indices (KPIs) and implement process improvements using Solution based on Lean Six Sigma, operations management, and operations research tools and methods.

\section{DMAIC Methodology:}

DMAIC methodology was used to improve the capabilities of current process. Based on data driven conclusions, future state has been established.

In Define phase, voice of customer and project charter were the tools used to decide the scope of work and define boundaries of improvement effort. In this phase, identification of key stakeholders, time lines, improvement priorities, and improvement targets were also done at the beginning of project. In Measure phase, team created data collection templates with respect to the area of improvement and worked on getting first hand data. Measuring the right data which can pin point location, occurrence point and rate of occurrence were 
termed as the critical parameters to decide the improvement priority and problem's location. In measure phase, team gathered historical data to come up with baseline for improvement. Measure phase data collection effort lead to more focused problem statement. Analyse phase helped in collecting causes of the problem to come up with root causes. Tools like Brain storming, cause and effect diagram, histogram and fishbone diagram were used to analyse phase of the improvement. In Improve phase, before and after process status were compared to develop and implement the process improvements. Improve phase not only generated the solutions but also gave feedback mechanism to check the effectiveness of improvements. Control phase stated a continuous improvement effort to sustain the demand variations. To incorporate major changes in process flow, it was suggested that the team should be able to analyse and anticipate the changes for further improvements.

\section{Improvement in On Time Shipment}

Improvement in On-time Shipment directly impact the whole supply chain process of the concern organisation. The respective data was collected from last seven projects history, which enabled the improvement team to find the root causes behind it. The DMAIC approach was followed to improve the On-Time Shipments (OTS). The detailed step wise procedure followed is as explain below.

\section{Define:}

If the products were shipped on same date as committed to customer, then it was considered as on time. If they were shipped after scheduled date, then shipment was not considered as on time shipment. Historical data of on time shipment for each project was collected and the approach of improvement was defined accordingly. The work flows for customer order process were analysed, starting from order confirmation until it was shipped. Also, the work flows were analysed by applying lean tools as value stream mapping; where non-value added activities, value added activities were identified (as shown in the Table 1 below). Any activities not adding value to product or service was considered as waste. It was decided to eliminates the non-value added activities in the order processing, to reduce the cost and cycle time.

Table 1 Value added and non-value added activities identified in define phase for improvement in OTS

\begin{tabular}{cc}
\hline Value added activities & Non-value added activities \\
\hline Creating work order & Checking physical count \\
\hline Assembly & Manually supplier selection \\
\hline Testing & Placing frequent purchase orders \\
\hline Quality checks & PO holding for sign off \\
\hline Packaging & \\
\hline
\end{tabular}

\section{Measure:}

Each product was measured and analysed differently considering the model or type of project like make to inventory, make to order, make as per schedule of spares requirement from customers. Some important root causes for delay in On-Time Shipments were found out and categorised into measurement issues, material, personal, environmental, methods and machines etc. as shown in Table 2 below. 
Table 2 Categorical Root-Causes for OTS

\begin{tabular}{cc}
\hline CATEGORY & ROOT CAUSE \\
\hline Measurement & -Configuration issue \\
\hline Material & $\begin{array}{c}\text {-Material shortage } \\
\text {-Parts failure }\end{array}$ \\
\hline Personal & -Sales-SCM time not considered \\
& -BOM issues \\
\hline Environmental & -Rework \\
\hline Methods & -Software issues \\
& -Engineering issues \\
\hline Machines & -PCB manufacturing \\
\hline
\end{tabular}

After collecting all data, the most affecting root causes like configuration issue, material shortage, parts failure, BOM issues etc. were categorised under major heads as listed in Table2. The measure phase started by developing a simple template to plot and track the data points of improvement for shipment, starting from sales order got approved from customers to shipping to analyze the areas of improvements, and quick wins.

\section{Analyse phase:}

The analyse phase started by collecting data of recent seven projects of the causes on delayed shipments. The fishbone diagram (or cause and effect diagram) representing the effect of these root causes was drawn as shown in Figure 2. Below Table 2 shows the causes for delayed in shipment and their occurrence.

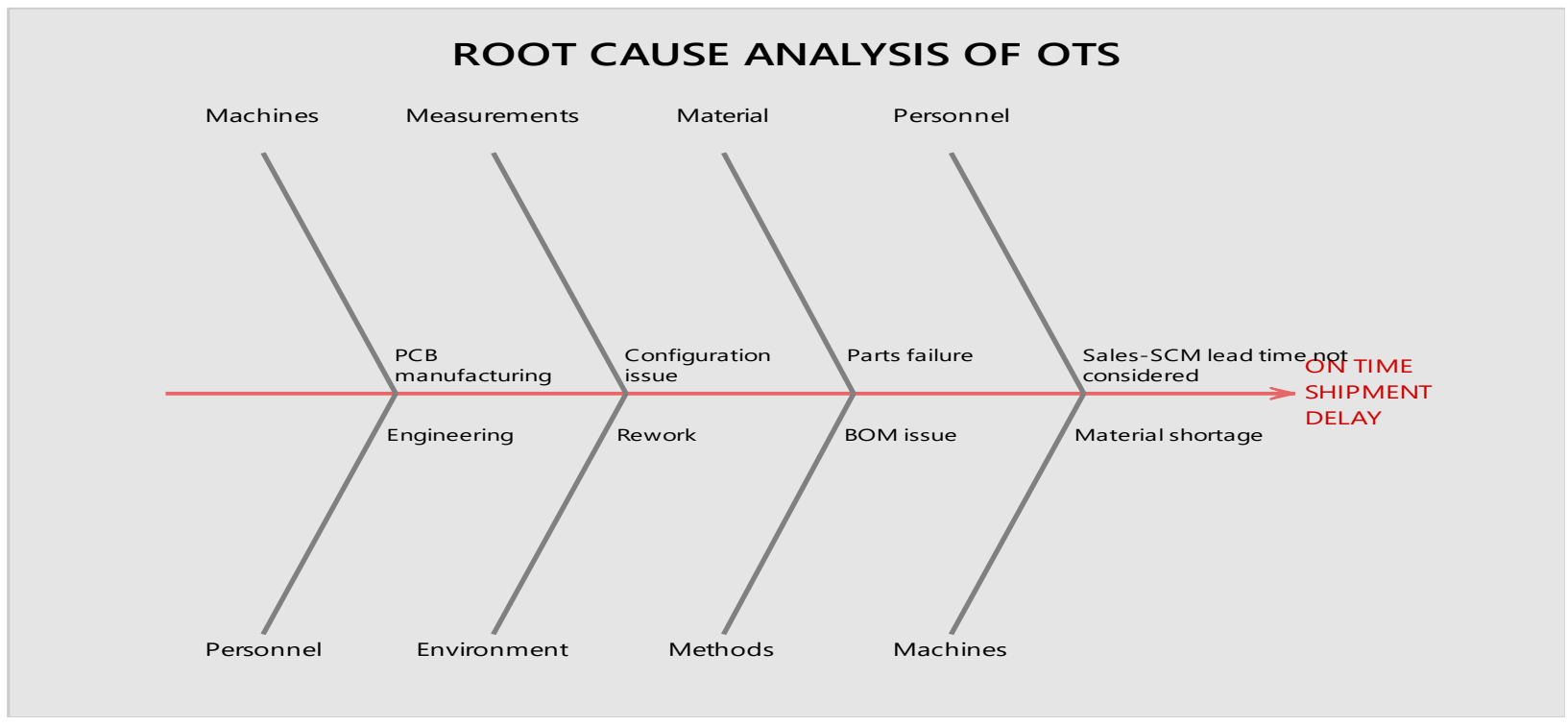

Figure 2: The fishbone diagram (or cause and effect diagram) for On-Time shipment delay

Table 3: Causes for delay in shipments and their occurrences

\begin{tabular}{ccccc}
\hline SR. NO. & CAUSE & NO. OF OCCURANCE & PDF (\%) & CDF (\%) \\
\hline 1 & Material Shortage & 6 & $22 \%$ & $22 \%$ \\
\hline 2 & Sales-SCM lead time not considered & 5 & $19 \%$ & $41 \%$ \\
\hline 3 & BOM issues & 3 & $11 \%$ & $52 \%$ \\
\hline 4 & PCB manufacturing & 3 & $11 \%$ & $63 \%$ \\
\hline 5 & Engineering & 3 & $11 \%$ & $74 \%$ \\
\hline 6 & Configuration issue & 2 & $7 \%$ & $81 \%$ \\
\hline
\end{tabular}




\begin{tabular}{ccccc}
\hline 7 & Rework & 2 & $7 \%$ & $89 \%$ \\
\hline 8 & Software issues & 2 & $7 \%$ & $96 \%$ \\
\hline 9 & Parts Failure & 1 & $4 \%$ & $100 \%$ \\
\hline \multicolumn{7}{c}{ TOTAL } & 27 & & \\
\hline
\end{tabular}

Material shortage and Sales-SCM lead time are the causes for delay in shipment that contributes to most towards the total cause. To minimize the effect on total cause, it was decided to concentrate more on these key causes and prioritize the other moderate factors/causes accordingly. Also, it was clear that the improvement in these areas minimise the overall delay in OTS. Pareto chart of issues for not having on time shipments based on above table was plotted and those causes were eliminated by root cause analysis and $5 \mathrm{~W}$ (What, Why, When, Where and How) technique (Figure 3).

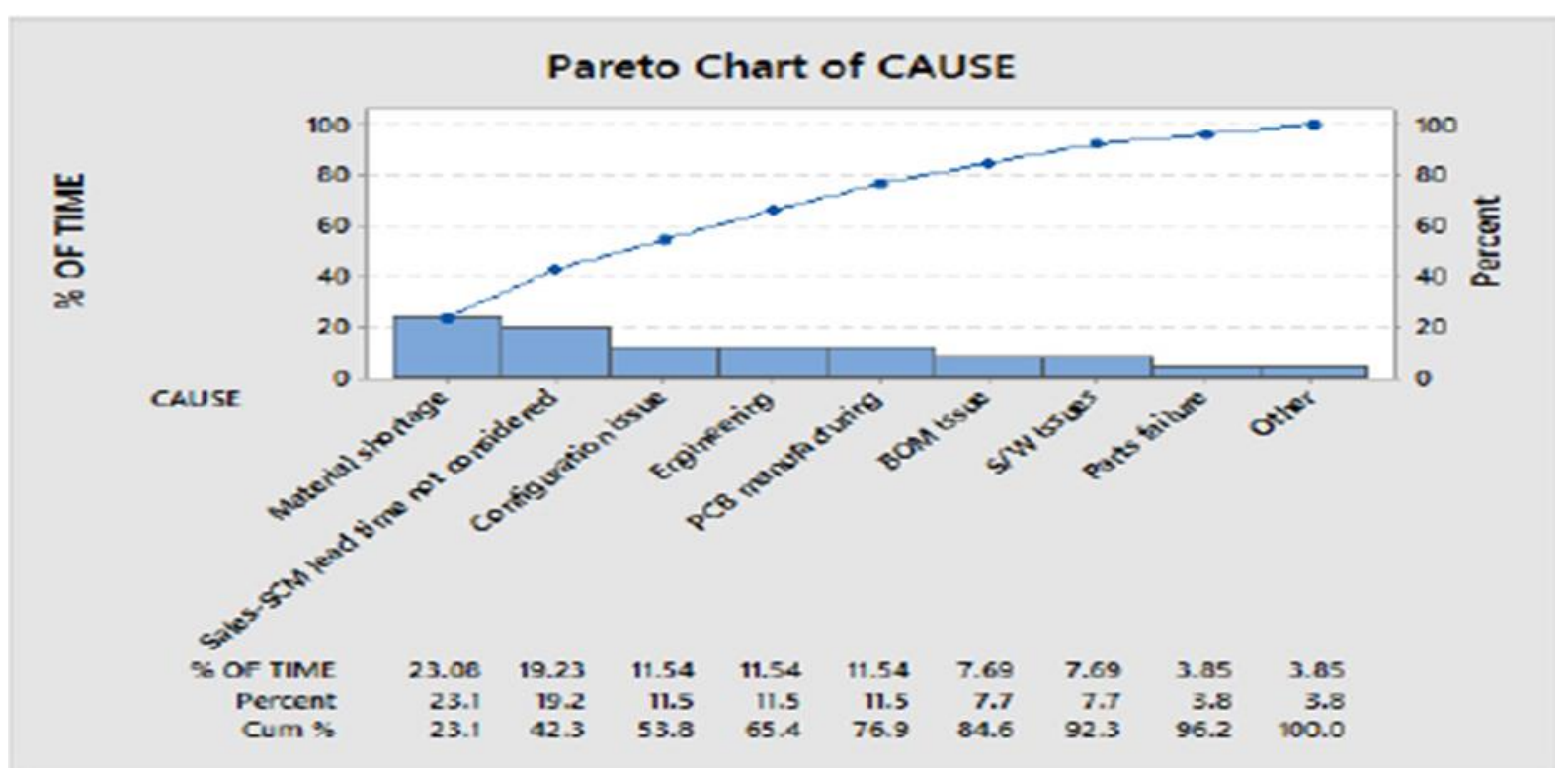

Figure 3 Pareto Analysis for causes of delay in On-time shipments showing the contribution of each cause.

\section{Improve phase}

According to Pareto chart (Figure 3), $81 \%$ of the causes are related to lead times, material shortages, and part failures, bill of material issues, configuration, and engineering issues. So, it was decided to improve these problems by understanding current process flows and developing new improved process flows to address the causes of delays

\section{Control phase}

Based on the Analyse and Improve phases, it was concluded that to sustain improvement in On Time Shipment, the organisation should have demand management tool for plan and schedule orders effectively, improved Sales and Operational planning, and efficient Material requirement planning..

\section{Physical Inventory Accuracy}

Physical inventory accuracy means the available on hand stock in Inventory and ERP system stock are equal. It helps to track all inventory flows and plan accordingly. It was decided to improve the current situation of inventory management and work to minimize the errors. Implemented new process to make sure data shown in the system will match physical count of data in inventory store. 


\section{Define and Measure phase:}

The organisation works on Tally-ERP9 software system. All the material purchase and accounting is done through this software. When the material is received physically from supplier or vendor, the exact count is inserted into the ERP system after quality checks as the routine procedure. This practice helps the organisation to keep track of material. Physical inventory accuracy means keeping the available stock in Inventory and stock in ERP system equal. It was decided to improve the current scenario in inventory management and work on methods to reduce defects and errors.

The physical inventory count had been taken which resulted into 53\% of inventory accuracy. The target for improvement in inventory accuracy was decided up to $95 \%$.

Cycle counting programs helped to identify the root causes of inventory accuracy variance. An ABC analysis was carried out to reconcile the inventory data. The introduction of inventory cycle count programs ensured the correctness of the inventory data. Some random audit checks were conducted to check the accuracy of inventory data. Efforts were made to check whether ERP system material count matches with on hand material count or not.

The primary goal behind Inventory cycle counting was to achieve excellence in service and keeping optimal internal operations to indirectly improve the inventory accuracy and overall effect on On-time shipment (Piasecki, 2003), some secondary objectives were set e.g. improvement in problems associated with processes regarding the material receiving and issuing for $\mathrm{R} \& \mathrm{D}$ or testing purpose, issues related to $\mathrm{BOM}$, correct on hand balance of material, etc.

Based on the inventory accuracy done and as discussed above, it was decided to analyse the causes of accuracy variance in process point of view. Causes for more than 63 item variances were collected to come to conclusion. It was decided to identify the major processes affecting the inventory count.

The causes behind the accuracy variance in the inventory record and their occurrences were found out and are listed in the Table 4 below. These various causes and their cumulative effect on the overall inventory accuracy were used to analyse and to take further corrective actions accordingly.

Table 4 Causes for material variance with their occurrences and probabilities of occurrence

\begin{tabular}{cccc}
\hline CAUSES & NO. OF OCCURANCE & PDF & CDF \\
\hline Work order status not updated & 57 & $42 \%$ & $42 \%$ \\
\hline Wrong inventory storage practices & 34 & $25 \%$ & $67 \%$ \\
\hline Material not received in system & 23 & $17 \%$ & $84 \%$ \\
\hline Material not found in store & 12 & $9 \%$ & $93 \%$ \\
\hline In-house borrowed material list not updated & 9 & $7 \%$ & $100 \%$ \\
\hline Total & 135 & & \\
\hline
\end{tabular}




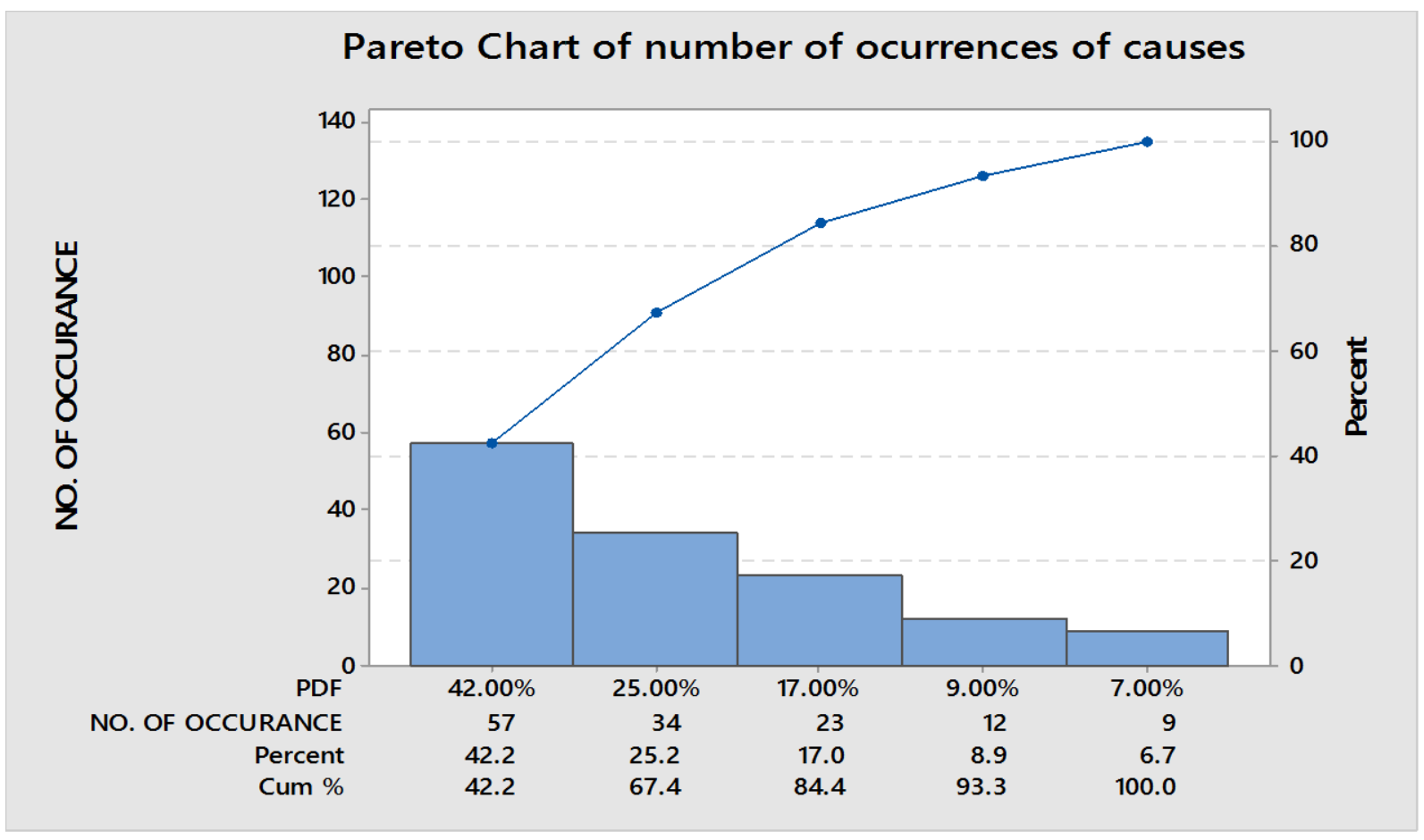

Figure 4:Pareto Analysis of inventory Cycle count variance

\section{Analyze phase:}

The root causes of the inventory accuracy variance were analyzed using various Six Sigma tools to figure out the key causes to make improvements in it.

After finding the root causes the required improvement action plans were suggested as shown in the table below. After implementing these action plans up to $30 \%$ increment in the current inventory accuracy was targeted.

Table 5: Further causes, Root causes and Actions required

\begin{tabular}{ccc}
\hline Cause & Root Cause & Action Required \\
\hline Work order status not updated & Irresponsibility towards work & $\begin{array}{c}\text { Increase product } \\
\text { availability with MRP }\end{array}$ \\
\hline Wrong inventory practices & No 5S practices & Need to have 5S program \\
\hline Material not received in the system & $\begin{array}{c}\text { Lack of 5S and low service } \\
\text { level, lack of } \\
\text { training/processes }\end{array}$ & $\begin{array}{c}\text { Train the employees with } \\
\text { processes and systems }\end{array}$ \\
\hline Material not found in store & $\begin{array}{c}\text { Not having cycle count, No } \\
\text { 5S }\end{array}$ & $\begin{array}{c}\text { Need to implement } \\
\text { scheduled cycle counts }\end{array}$ \\
\hline In-house borrowed material not updated & $\begin{array}{c}\text { No material transaction for } \\
\text { In-house use }\end{array}$ & $\begin{array}{c}\text { Make a standard process } \\
\text { for In-house borrow }\end{array}$ \\
\hline
\end{tabular}

The corresponding actions taken to improve the causes of inventory accuracy variance are explained as follows.

Work order status not updated:

It was observed that partially assembled orders were forwarded to assembly and to technicians who were building partial units. Once rest of the material arrived they started rebuilding those half-completed units. This scenario created waste of semi-finished panels, as these panels cannot be forwarded to next stage of process of 
testing and/or Burn-In. So to avoid this conflict in the production process a strategic procedure was suggested and followed for availability of material with MRP. Which resulted

Wrong inventory storage practices:

The material was stored at one primary location with the bin, but due to size and volume of the products, workers were using more than 2 locations to store the material in inventory storeroom. This indicated the rigorous need of $5 \mathrm{~S}$ program for inventory store room and production floor, with considering the requirement of material storage (size and volume). Implementation of "Tags" for keeping inventory count and secondary storage location and discipline was also suggested.

Material not received in the system:

It was observed that many a times the material was directly issued to the concern assembler to reduce more delay in the process at that moment without receiving it in the system (Tally ERP-9).

Material not found in stores:

The material which was already scrapped or with aging more than 6 years, was fitted under this category. Considering life of electronic component and the pace with which technology is changing we discarded this material and suggested to take loss on balance sheet.

In-house borrowed material not updated:

It was suggested that the material which is utilized by in-house projects or R\&D department should be transacted on debit order or sales order to keep track of material count in inventory stockroom, which in this case was not followed properly. As per the schedule, Inventory cycle count program was carried out. Also, implemented action to be required for causes of variances and achieved the target result of $94 \%$ of inventory accuracy.

In addition, the Finance or Business Manager is responsible for ensuring that segregation of duties are maintained throughout the inventory process to promote the safeguarding of the assets, protection of employees, and objective reporting of inventory.

\section{S Implementation}

Many manufacturing facilities have opted to follow the path towards a "5S" workplace organizational and housekeeping methodology as part of continuous improvement or lean manufacturingprocesses.5S is visual management technique used to keep work area organized all the time.

"A place for everything, and everything in its place" is the mantra of the 5S method, and storage and workspace systems allow improved organization and maximum use of cubic space for the highest density storage.

$5 \mathrm{~S}$ is a system to reduce waste and optimize productivity through maintaining an orderly workplace and using visual cues to achieve more consistent operational results. The $5 \mathrm{~S}$ program was conducted in three phases of implementation as explained follows (Maclnnes, 2002).

The 5S system is a good starting point for all improvement efforts aiming to drive out waste from the manufacturing process, and ultimately improve a company's bottom line by improving products and services, and lowering costs. 


\section{Phase 1}

The 5S GAP analysis was carried out and 5S audit form was developed to carry out the audit. The criteria for measuring $5 \mathrm{~S}$ score were $5 \mathrm{~S}$ culture by adding value, Overall facility, Storage and arrangement for equipment and devices etc. The "Red Tag" program was initiated and a dedicated "Red Tag Area" was assigned to sort and categorize the items, machines and tools on the work floor in accordance with its need or use.

The management was suggested to create $5 \mathrm{~S}$ assessment board so to share visual information related to progress of the program. The main objective behind this was to track and make corrective actions to improve the overall $5 \mathrm{~S}$ score.

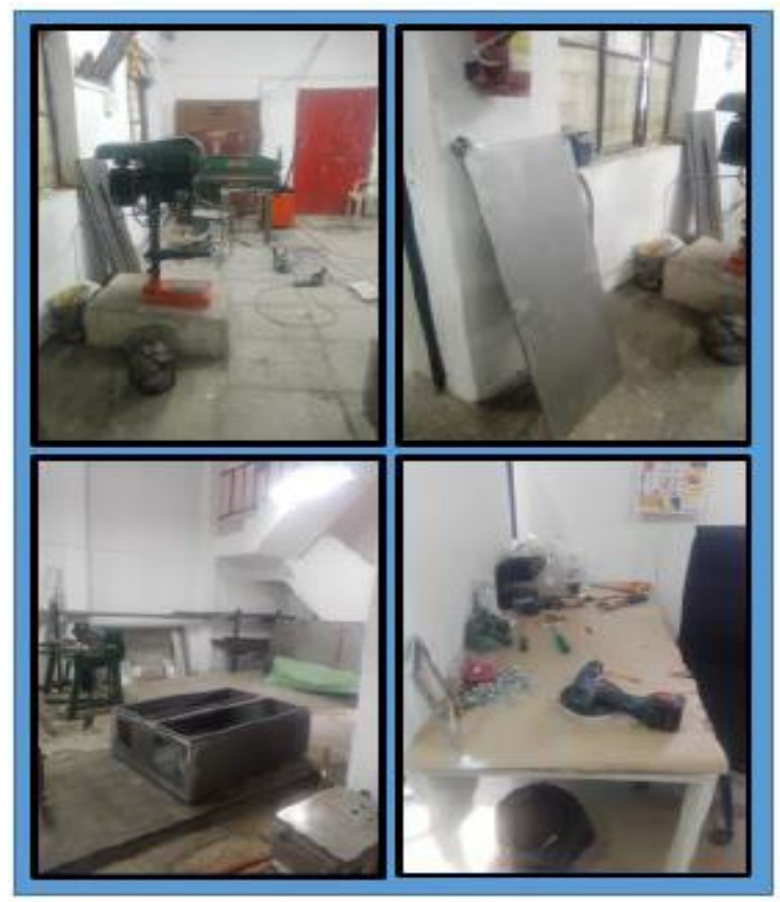

Figure 5:Workplace before and after initiating 5S program

\section{Phase 2}

The employees of the organisation were divided into teams and the leader was assigned to carry out the improvement. They were assigned to an area of improvement in the concern department and were asked to score their respective area on daily basis by themselves with the condition that they must give score to themselves regularly until their self-score reaches to 65 out of 75 .

The $5 \mathrm{~S}$ weekly morning meetings of employees were scheduled to discuss on more improvement opportunities in their area. The 5S workplace audits were conducted on every alternate week. In the meetings employees were more encouraged every time to let them proactively participate and share their views in the process of implementation. 

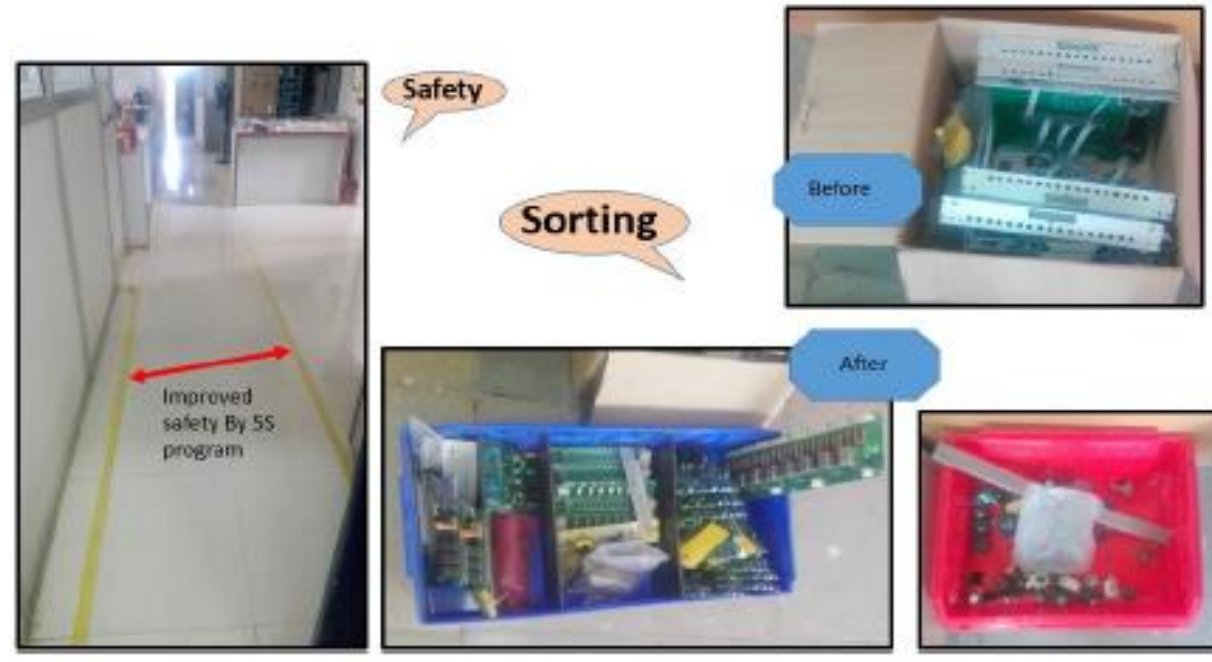

Figure 6:Improvement with 5S program

\section{Phase 3}

It was decided to address the issues of not having good score on $5 \mathrm{~S}$ by addressing the process related issues. Implementing $5 \mathrm{~S}$ culture improved the quality of products and service by preventing the errors and defects before they occurred.
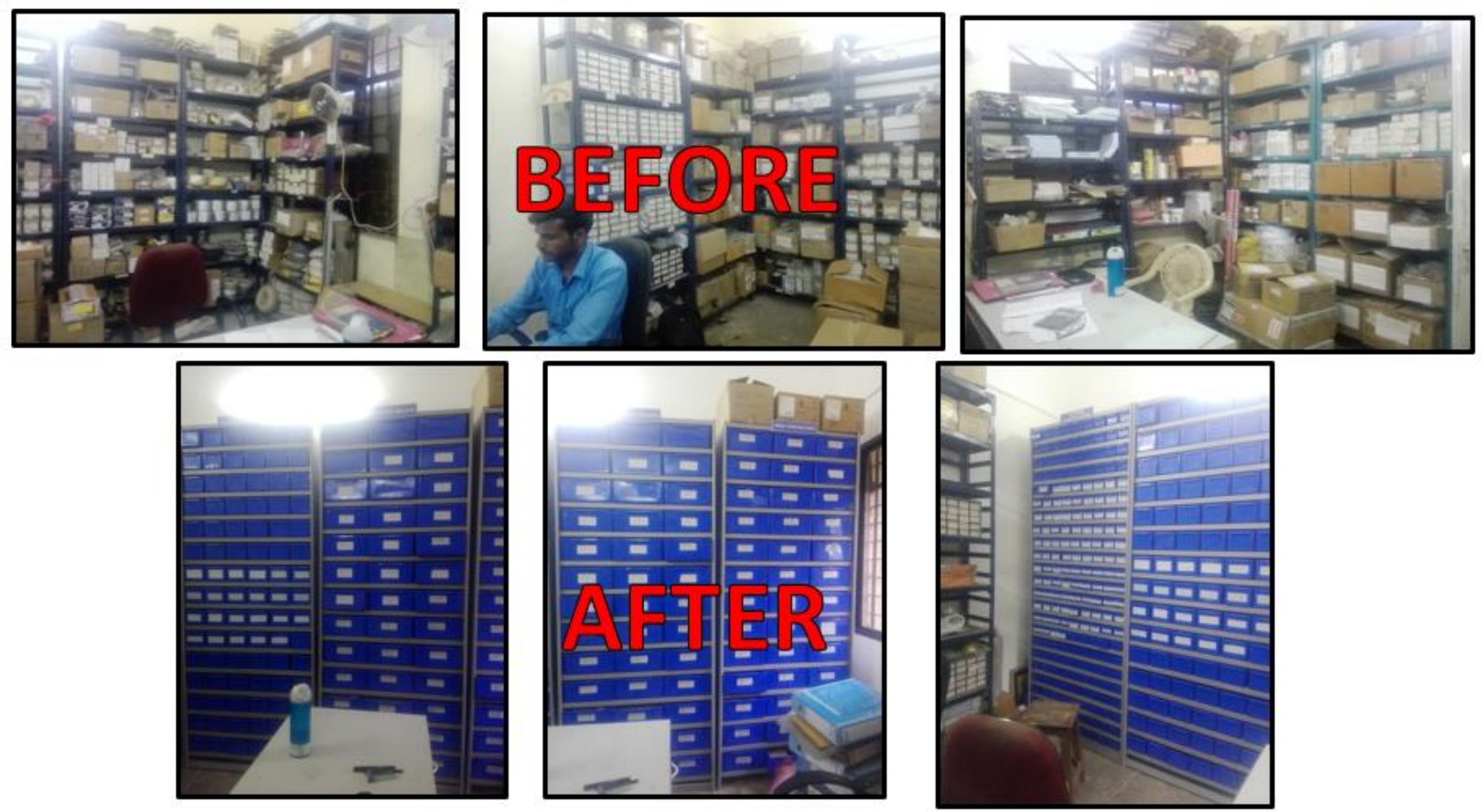

Figure 7: Before and After scenario of implementing 5S program in inventory stock room

The Figure 5 shows how the $5 \mathrm{~S}$ program implementation improves the existing scenario of material store room. It also improved employee involvement, health, and safety, thereby reducing hazards in the organization.

The overall 5S implementation was found satisfactory and its effect was helpful in improvement of KPIs i.e. inventory accuracy, material availability, On-Time shipment (OTS). 


\section{Conclusion}

Lean Six Sigma tools helps to improve supply chain performance by investigating the reasons for process breakdowns, and thereby eliminate their root causes. Improvement processes mainly concentrate on lead time and material availability issues.

In addition to Lean Six Sigma tools and methods, which were based on statistical analyses, the importance of implementing a Lean supply chain was discussed in detail. Analysing the data to predict the occurrence point and the rate of occurrence helped in identifying the root causes associated with OTS. With implementation of DMAIC methodology it was clear that improvement in Material Shortage and SCM lead time, resulted in reduction of overall delay in OTS. The integration of Pareto analysis with suggested improvement action plans can improve the current inventory accuracy by $30 \%$ and $20 \%$ in OTS. Some implementations are still under process and more improvement is expected in future.

\section{Acknowledgements}

I would like to express my respect and sincere appreciation towards my colleagues, faculty, and all employees of the industry for their encouragement, support, and direction.

\section{References}

Piasecki, D. (2003). Inventory accuracy people, processes \& technology. OPS Publishing.

Vicky B. Sardar, Dr. N.R. Rajhans, 2017, Study of the Behaviour of Intermittent Demands, Industrial Engineering Journal [ ISSN 9070-2555], Volume 10, issue 2, pg 35-39

Ameya Pathak, Tushar Prabhu, Vicky Sardar, Dr N. R. Rajhans, 2017, Inventory management for newly started service station, International Conference on Manufacturing Excellence 2017, ISBN NO: 978-93-24457-41-5

(Inventory turnover) Retrieved from http://en.wikipedia.org/wiki/Inventory_turnover

Martin, J. (2007). Lean six sigma for supply chain management the 10-step solution process. New York: McGraw-Hill Companies.

Antony, J.; Escamilla, J.L.; Caine, P.; , "Lean Sigma [production and supply chain management]," Manufacturing Engineer, vol.82, no.2, pp. 40- 42, April 2003 DOI: 10.1049/me:20030203 